\title{
Children's Magical Realism for New Spatial Interactions: Augmented Reality and the David Almond Archives
}

\author{
Kimberley Reynolds ${ }^{1}\left[\right.$ ] Tom Schofield $^{2} \cdot$ Diego Trujillo-Pisanty $^{3}$
}

Published online: 29 June 2019

(c) The Author(s) 2019

\begin{abstract}
This article draws on a multi-disciplinary project based on the David Almond archives at Seven Stories, the National Centre for Children's Books in Newcastle upon Tyne, UK. The project combined archival research, augmented reality (AR) technology, Almond's magical realist writing and experimental workshops to explore whether AR can enhance young people's engagement with archives and literature. In the process it highlighted the extent to which Almond's fiction is itself a form of augmentation that represents a particular geographical location-the North East of England-in ways that challenge official accounts of that place. This aspect of Almond's writing corresponds to what Michel de Certeau describes as tactical spatial practice and is closely associated with some forms of AR.
\end{abstract}

Keywords David Almond · Augmented reality $\cdot$ Magical realism $\cdot$ Spatial practice

Handling EIC name: Victoria de Rijke.

Kimberley Reynolds is Professor of Children's Literature in the School of English Literature, Language and Linguistics at Newcastle University in the UK. She is a Past President of the International Research Society for Children's Literature and in 2013 received the International Brothers Grimm Award for her contributions to the field of children's literature research. Currently she is Senior Editor of International Research in Children's Literature. Recent publications include Children's Literature in the Oxford University series of Very Short Introductions (2012); Left Out: The Forgotten Tradition of Radical Publishing for Children in Britain, 1910-1949 (2016) and Reading and Rebellion: an anthology of radical writing for children, 1900-1960 (2018), co-edited with Michael Rosen and Jane Rosen.

Tom Schofield is an artist, designer and researcher working on emerging and open source technology, participation and cultural data in public space. His practice is engaged with contemporary issues in post-digital culture including network politics, network temporality and critical infrastructure.

Diego Trujillo-Pisanty is an artist, designer and researcher whose work focuses on the cultural and ideological implications of emerging technologies. His research explores processes and methods for designing technological devices and interfaces that are provocative and meaningful to users.

Extended author information available on the last page of the article 
When, in the spring of 2018, David Almond donated his literary archive to Seven Stories, Britain's national museum and archive for children's books in Newcastle-upon-Tyne, he probably imagined its contents being used by lone scholars sitting at desks and sorting through his papers for the purpose of writing articles and monographs. In fact, the first foray into the Almond archive resulted in scenes as strange and transformative as anything David Almond has written, and all taking place in the Ouseburn Valley where he grew up and where most of his fiction is set. The research was part of a project devised in response to a challenge by UK research councils to demonstrate how the arts and humanities can inform the development of new immersive technologies, including their role in the work of increasing access to and use of the assets of cultural organisations. ${ }^{1}$ Called 'Children's magical realism for new spatial interactions: AR and archives,' it enabled researchers from Newcastle University's Children's Literature Unit and Culture Lab (the University's centre for research in creative digital practice) to join with members of Seven Stories' collections, exhibition design, and creative events teams to run a series of six experimental workshops. The workshops involved children between the ages of seven and fourteen, some of their parents and teachers, Seven Stories staff, and local app developers. The workshops fed into the development of an interactive smartphone app, Magical Reality, which accompanied both 'Where Your Wings Were', a Seven Stories exhibition about David Almond, and 'Winged Tales of the North', a related sculpture trail winding through the Ouseburn Valley around Seven Stories (Fig. 1). At a number of levels, the project used children's literature and technology to find new ways to tell stories about places and their links to the past.

The app employs Augmented Reality (AR) technology, a digital means of mixing real and virtual environments by adding digital layers to the physical world, perhaps the most familiar example being gaming applications such as Pokémon Go. In this case, the Magical Reality app places three-dimensional digitally generated objects based on notes and sketches from David Almond's working papers in and around the Seven Stories visitor centre and the sculpture trail. Users move through the space with smartphones onto which the app has been downloaded. A series of prompts directs them where to point their phone and as the coordinates align, a magical realism inspired item from the Almond archive appears and performs some kind of action related to the space. Finding the items proved so engaging that users had to be reminded to watch for hazards, including traffic on the roads, as they explored the trail!

At an intellectual level for the researchers, Almond's work, magical realism and AR technology underpinned the outcomes and so in the following discussion, this background is set out first, to contextualise the applied dimension of the research. Equally important, however, was the need to engage the children and young people

\footnotetext{
1 The call for projects, 'Next Generation of Immersive Experiences' was co-funded by the Arts and Humanities Research Council (AHRC) and the Engineering and Physical Sciences Research Council (EPSRC) as part of Research and Partnership Development. Projects had to be completed between June and December, 2018. https://ahrc.ukri.org/funding/apply-for-funding/archived-opportunities/researchand-partnership-development-call-for-the-next-generation-of-immersive-experiences/.
} 


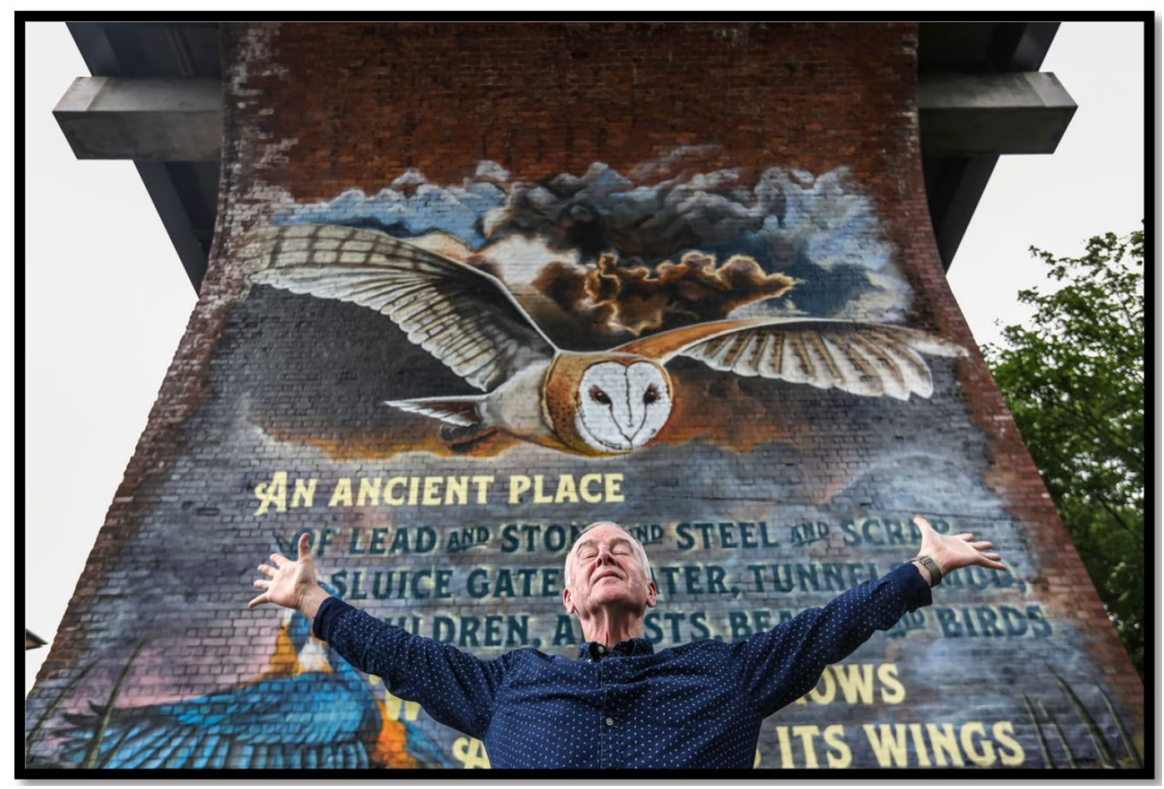

Fig. 1 Image of David Almond with a mural from 'Winged Tales of the North'

with archival material with a view to expanding the way archives are used, by whom and to what ends. Emphasis on archives also sets the project apart from other experiments with narrative that bring together digital and print texts, the most notable being These Pages Fall Like Ash, a 2013 project set in Bristol in which users read instalments in a fiction based in the city in the two media (see Abba and Speakman, 2013; Butler, 2018). Ultimately, all of these interests-Almond, archives, magical realism and $\mathrm{AR}$ - had to coalesce in the app, for which workshop participants were co-developers in terms of content selection and user satisfaction. These aspects of the project comprise the second part of the discussion, where the workshops are also described.

Creating the app was only one part of the research project, however. The workshops and development process drew on some of the more culturally meaningful uses of AR. For instance, AR digital graffiti has been used at historical sites to incorporate stories and voices absent in official accounts, changing how these sites are understood and whose stories they tell (see Liao and Humphreys, 2014; Løvlie, 2009). It was this aspect of AR that gave the project its focus on the David Almond archive; Almond's work was chosen for the project for its affinities with AR. A starting premise of the research was that his children's books function as a literary form of AR in the way they attempt to 'change the narration of existing place' (Liao and Humphreys, 2014, p. 14). This understanding grew in the course of the project as the lens of AR highlighted the extent to which Almond's writing incorporates stories, voices and experiences left out of some longstanding representations of the region, not least those underpinning some government policies and resourcing strategies. Borrowing from Michel de Certeau's theories of spatial practice, Almond's 
fiction can be understood as creating 'tactical' spaces, for in them readers imaginatively move through the geographical landscape that provides his settings in ways that challenge or subvert official (what de Certeau calls 'strategic') meanings (1984, p. 37).

\section{Tactical Writing, Archives and AR}

Almond's use of magical realism made for some highly productive comparisons and interactions with AR, which in turn identified synergies between AR and literature more widely. Additionally, the local nature of Almond's work gave an immediate and rich dimension to how the app works since it was being developed with children from the locality, most of whom came with some knowledge of Almond's books for children and young people. Thinking of Almond's work alongside AR highlighted the extent to which he 'augments' the places, spaces and memories that feature in his fiction. This meant the AR dimension of the project comprised a two-way flow between his writing and the app. Exploring the similarities and connections between $\mathrm{AR}$ and magical realist writing for children showed how the two forms complement and extend each other. The resulting insights grew from and informed the workshops as well as what the project revealed about how youthful audiences can be engaged in archive-based projects and exhibitions. For children's literature scholars, a key finding was the way using AR with Almond's writing provoked new ways of thinking about his work and magical realism as a literary genre while also creating new opportunities for encouraging children and young people to read. While the focus was on Almond and magical realism, it would be possible to use AR with a range of genres and authors, from works grounded in history through myths, legends, biography, detective, ghost and mystery stories through writing that blends fiction and non-fiction and some forms of pure fantasy. As it happens, Almond's work often combines several of these genres. Not all kinds of writing are suitable for this approach, however. For instance, it would be hard to do anything substantive with works set exclusively in another universe. With regard to exploring tactical spaces, there are distinct advantages in working with material based in clearly identifiable localities.

To understand the tactical nature of Almond's writing, it is necessary to think about both past and present images of the North East of England. Once this region was a powerhouse of the British Empire. Ships were built there, coal mined, and armaments manufactured. The turn of the last century saw its fortunes decline as the number of Britain's dominions decreased more or less in tandem with the loss of British industrial pre-eminence. Heavy industry, mining and the full employment they generated all but disappeared. Unemployment further ravaged the area in the 1980s when then Prime Minister, Margaret Thatcher, took on the mining unions and in the process destroyed long-established mining communities. The closure of mines, factories and shipyards is relatively recent, but already, once thriving and vital industries have been reduced to rusty ruins. Their architectural remains and physical legacies litter and undermine the landscape alongside more picturesque 
evidence of Roman occupation and early Christian activity. This backdrop-ancient and modern, romantic and decrepit_-provides the setting for David Almond's work.

Typically, sites of post-industrial decay inspire writing that features the impoverished and marginalised parts of society; a steadily expanding precarity that feels cut adrift from society (Duchene, 2016, n.p.; Policy Exchange, 2012, n.p.). The people of England's North East, with their strong local accents and lack of traditional forms of cultural capital, have long been depicted as outliers to more affluent parts of Britain. David Almond describes the people and places he writes about as 'pretty much excluded from mainstream English life' (Latham, 2006, p. 10). By contrast, his magical realist stories and novels turn the region into a place where ordinary people and everyday events are given mythical resonance. His North East is no post-industrial rust belt, but a taproot that reaches down into history, linking past and present.

Connecting to the past is a key theme in Almond's work, where defunct factories, derelict mines, disused quarries, and industrial wastelands become unofficial lieux de mémoires/sites of memory: places 'where memory crystallizes and secretes itself' (Nora, 1989, p. 7). For Pierre Nora, sites of memory help mediate the rapid changes that characterise modernity, producing the destabilising sense that nothing is secure, all is relative, and 'anything and everything may disappear' (p. 7). To that end, and exemplifying Michel de Certeau's theories of strategic spatial practices, governments and historians invent or invest in places of memory associated with official versions of history-museums, memorials, eternal flames, commemorative gardens - to create a sense of cultural coherence and unity. For Nora however, true sites of memory are not deliberately fashioned but, 'borne by living societies,' belonging not to whole nations, but to particular groups and spaces (Nora, 1989, pp. 8-9). The places where memory is secreted in Almond's work are precisely of this type; their significance is derived from actual, collective, memories imbued with the symbolic aura characteristic of lieux de mémoires. As Nora describes, Almond's mingling of past and present creates an empowering sense of connection and continuity, free from the dictates of chronology and the orderly organisation of historical records. Often he does so by placing layers of ancient story over real places, just as the Magical Reality app inscribes objects in the local landscape.

AR technology is still evolving meaning the time, cost and technological infrastructure it requires are considerable. Currently, AR gains much from being linked to literary works. For instance, as it moves from the page to real-world locations, the objects the Magical Reality app generates are only able to interact with their geographical locations in quite basic ways. It gains considerably through its associations with Almond's magical realist fiction which textually augments his version of the North East in complex and emotionally sustaining ways. For instance, in A Song for Ella Grey (2014), a retelling of the legend of Orpheus and Eurydice, he superimposes the entrance to Hades over a real culvert in the Ouseburn Valley. Through it Orpheus, still a beautiful lyre-playing youth but now a wanderer in present-day Northumberland, descends in an attempt to return Ella Grey, his Eurydice, to the land of the living. One of the spider diagrams for the book found in the archives (spider diagrams are Almond's usual way of brainstorming in preparation for writing) begins with a note that reads: 'realistic, but inexplicable/transcendent forces (love, power of music) within/Orpheus draws out these forces from others'. Elsewhere the 


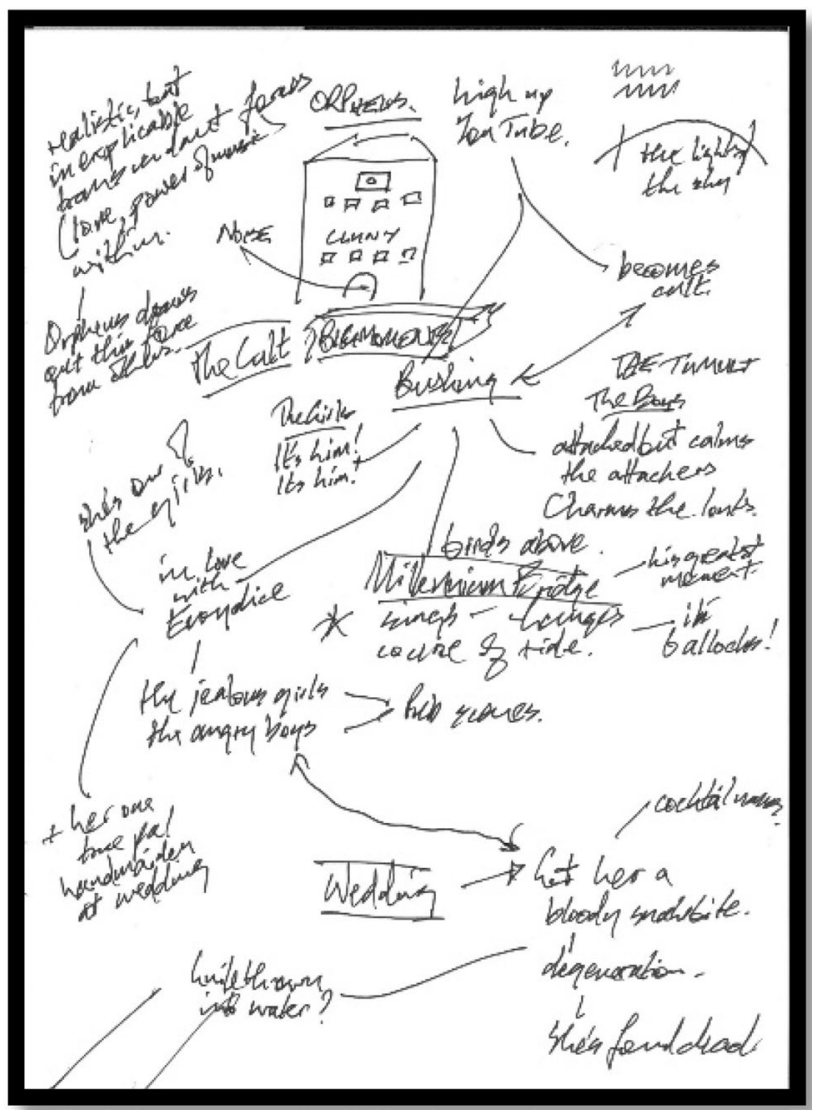

Fig. 2 A page from David Almond's notebook showing ideas for A Song for Ella Grey

diagrams include a drawing of the Cluny pub, just two buildings away from Seven Stories, and references to a local bridge, a beach, Ovid, Orpheus, Eurydice, and plot elements from the Orpheus myth (Fig. 2). Even at this early stage the ancient tale is augmenting both the place and the world the characters inhabit, and through the conventions of magical realism, the inexplicable and transcendent are accepted as real. The AR app aims to achieve a similar effect so, for instance, Almond's sketch of the Cluny appears as a pub sign and the building's past use is referenced by the accompanying sound of a printing works. Seeking out the AR objects, then, becomes a way of exploring the landscape, past and present, but the satisfaction of doing so is enhanced for those who know Almond's stories.

Uncertainty and transformation are central features of magical realism and it is not difficult to understand the genre's appeal for David Almond. At an everyday level, he is confronted with the damage wrought by poverty, lack of opportunity, and the toxic residues of the old industries. The 'magical' dimension allows him to share his sense of what lies beyond the obvious problems and limitations his characters 
experience. No matter how far they move from consensus reality, his central characters are shown to be loving and loved, capable, more inclined to wonder and awe than despair, and endowed with dignity and the ability to survive. Some are also visionaries; they see the world differently from most, and Almond uses magical realism to give their visions substance and efficacy. In Kit's Wilderness, for instance, John Askew, an adolescent who belongs to one of the old mining families, is both the 'bad boy' of the local school and a talented artist who, like a modern-day William Blake, sees beyond the limits of rationality. John is a kind of human site of memory; his drawings of 'the old life in the pit below...the hunched bodies of boys and men in the tunnels' (Almond, 1999, p. 14) document the mining past of the community, but his realistic depictions do not come from research. John seems to have intimate knowledge of their lives and what they endured. For him, the community is populated with the ghostly figures of children who once worked - and diedin the mine. He tells Kit, "You'll come to see there's more.... You'll come to see the others that walk beside us in the world" (p. 11). His drawings ensure past people and events are remembered more effectively than the local memorial to a mining disaster in which 117, including many children, died.

Across a range of characters and times, Almond shows that landscapes scorched by chemicals, scarred by mining, and disfigured by debris from old buildings and infrastructure can be places of creativity and mystery and beauty. Characters with imagination, energy, empathy, and the willingness to take risks are granted the capacity to see beauty and meaning in their everyday worlds: to see space tactically. This ability comes to Allie, one of John's and Kit's classmates and herself a promising actress, at the end of the novel, causing her to exclaim, "It's beautiful, isn't it?... The place we live" (p. 226). But even those with the capacity have to learn to look. This is as true for those growing up in Almond's North East today as it is for the characters in his books; his work shows readers how to look at the world around them and to see the history and qualities that have been effaced by neglect and disuse. At some level, the stories suggest, the past is still there; an unseen presence that can be accessed through creativity. The Magical Reality app gives this insight form and presence in Almond's landscapes by bringing literary depictions of place into everyday reality, renewing the sense of place and anchoring the texts.

Learning to look lies at the heart of both Almond's fiction and Magical Reality. In the books, instruction is often explicit: Kit's grandfather shows him how to read the landscape and soon he realises, 'the evidence of the pit was everywheredepressions in the gardens, jagged cracks in the roadways and in the house walls' (p. 18). His connection with the landscape literally deepens when Kit and John Askew are lost for 24 hours in the old mine that was once the centre of their village. While they are underground, Kit has a bizarre and hallucinatory but restorative experience that sees him interacting with those who have lived there before. Many of Almond's books similarly show characters having inexplicable experiences when they plumb or excavate the ground beneath city streets, brownfield sites, abandoned mines, quaysides, and urban wastelands. While digging in the mud around the Black Middens, a rocky outcrop at the mouth of the river Tyne where many ships have been wrecked, Mouse, one of the orphaned children in Heaven Eyes (2000), uncovers a petrified body. She and her companions decide the man was once a saint from the 
early days of Christianity in the North East and believe he comes to their aid when they need to find a way to manage and commemorate the corpse of 'Grampa', the old man who has been helping them. In Clay (2005), troubled Stephen Rose, whose father has died suddenly and whose mother is deranged, reaches 'down deep into the milky water' of a pond in an old quarry to extract ancient clay. He uses the clay to fashion, first little figures that apparently come to life, and then a great Golem who Davie, the central character, sees walking the streets of his home town. Whether his powers are real, an illusion (he comes from a line of hypnotists), or a figment of Davie's imagination, the characters are as clear to Stephen as the AR objects are to those using the Magical Reality app.

These supernatural events turn seemingly insignificant aspects of the urban landscape into accidental sites of memory. Stories become acts of witnessing and remembering, even though what is being remembered is often fugitive in much the same way that an AR image is: seen, and then gone when the user moves on or turns off the app. So, for instance, at the start of A Song for Ella Grey, Claire writes, 'I'm the one who's left behind. I'm the one to tell the story' (Almond, 2014, p. 3). Davie says of his experiences with Stephen Rose and the Golem that he has learned that 'crazy things can be the truest of all' (296). Similarly, Blue Baker begins Almond's graphic novel The Savage with the words, 'You won't believe this but it's true' (Almond, 2008, p. 7).

Far from a place of redundancy and dereliction, David Almond's fictionalised North East is populated by individuals who interact with gods, angels, saints, and figures from legend. His stories defy strategic accounts of the area as anachronistic and dependent, reshaping in engaging and powerful ways the stories of those living in disadvantaged and overlooked post-industrial cities. They create sites of memory and add markers to the contemporary landscape, encouraging readers to think positively about the geographical place which Almond writes about. This tactical version of the North East infuses the Almond archive, meaning that users of the Magical Reality app who are familiar with his writing add their own layers of meaning to the digital objects they locate. As this project demonstrates, AR and literary texts together generate a more complex, satisfying and potentially empowering imaginative space than either can do independently. Its findings build on previous research which suggests that AR encourages users to relate real places to literary texts and may encourage new ways of shaping the cultural landscape (see, for instance, Abba and Speakman, 2013; Cole, 2016; Løvlie, 2009).

Magical Reality begins to exploit AR's potential to visualise similar kinds of transformations; to fill in and animate historical sites. This is one reason why AR is proving so popular with the heritage industries as, for example, the England's Historic Cities project (see http://www.heritagecities.com/stories/explore). AR can be experienced simultaneously by users of different ages, abilities, backgrounds and cultures, but its capacity for narrative is still evolving. It is notable that Pokémon Go disregarded entirely the opportunity to think about how narrative, technology and public space come together. The creatures placed in the world of Pokémon Go were assigned their positions partly as a consequence of algorithmic decisions about game play and partly as a consequence of sponsorship tendering with chains including McDonalds and Starbucks (Zuboff, 2018, p. 316). Through its alliance with 
David Almond's writing and archive, by contrast, Magical Reality highlights the importance of developing the possibilities for future spatialised AR fictions.

\section{Magic, Texts and Technology: Developing Magical Reality}

The project was in many ways an experiment to test whether there are congruities between David Almond's work and AR technology and if so, whether these could be used to create new experiences of space for audiences. It also helped determine how an AR interpretation might affect Almond's texts. With this in mind, the project began by identifying facets of his books which could serve as starting points for such an exploration and thinking about how these related to the archival material in the David Almond Collection at Seven Stories. It was soon apparent that characters, atmosphere, plot, style, and illustrations all had potential for the project. These exist as published, known and so to some extent finished features. By contrast, items from the archive were treated as raw material, capable of being extracted, resituated, interpreted, and recombined for audiences beyond scholarly contexts. In combination with the affordances of AR, this way of working made it possible to think about items from the archive as part of material culture as well as the germs of literary texts.

The archive items acted as anchor points, both in space and in the creation of new stories. There was also a productive collision between magic as an expression of the unseen and the archive as a collection of papers that is normally only seen by the experts and scholars working with them. This double 'hiddenness' led to the decision digitally to embed aspects from the Almond papers in public space, so making them newly and differently visible. The movement between invisible and visible also enabled the project to explore relationships between real, localised space in Almond's work and broader ideas of magic and its presence in magical realist fiction.

The app was trialled in the final two workshops (detailed below) and launched in September 2018 as one of the concluding events in a huge, summer-long cultural festival celebrating the North East of England. ${ }^{2}$ Far from isolated academics then, David Almond's archives were first used to engage groups comprising school children, families, digital designers, researchers from other cultural organisations, university students and staff, and members of the general public. With smartphones in hand they explored the area around the Seven Stories visitor centre and 'Winged Tales of the North' trail, locating selected 'objects' (images, phrases, items) from the archives to which AR technology added visual, animated and audio elements. The items were selected for several reasons: a reference to Almond's work that would be clear to those familiar with it; because the content was suggestive of magical realist narrative logic; an obvious connection to the area, or because it had proven

\footnotetext{
2 The Great Exhibition of the North was set in Newcastle Gateshead. It lasted 80 days and reached millions of real and virtual visitors. See https://getnorth2018.com/great-exhibition-of-the-north-2018-engag es-millions/.
} 


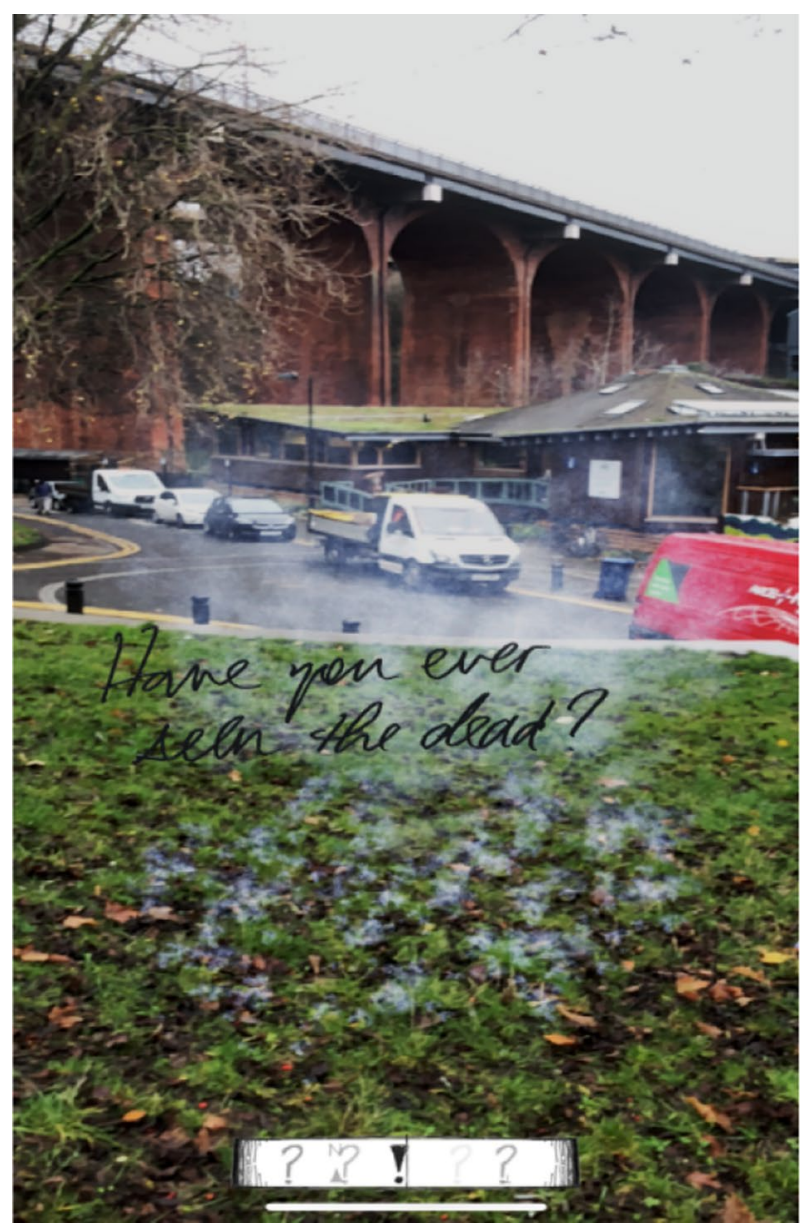

Fig. 3 Screen grab of 'Have you ever seen the dead?' from Magical Reality

particularly effective during the workshops. So, for instance, the bird from My Dad's a Birdman (2007), reflected children's interest in that illustrated story in which bird motifs show a father and daughter working through their grief over the death of their wife/mother.

Almond's archives are a mix of longhand book drafts, messy diagrams, enigmatic half sentences and small drawings. Taken out of context, many parts of the texts seem to suggest new stories or situations lending themselves to new interpretations when digitally placed in physical locations. Magical Reality uses several such extracts. For instance, one features the question, 'Have you ever seen the dead?' (Fig. 3). The words hover in space a metre above the ground and are surrounded by slowly billowing smoke and so act as a kind of 'situated prompt,' exhorting viewers to consider the encounter with the object as a site of remembering, real or imagined. The question might be understood as something for the 
user of the app to answer, a link to one of Almond's stories, or as the beginning of some as yet untold story. This doubleness and the words' relationship to a particular environment at a given time are characteristic of David Almond's creative practice; in Magical Reality they have been designed to be experienced similarly both by those familiar with his writing and those who have not read his work. So, for instance, the words 'Have you ever seen the dead?' appear in a quiet grassy area, strewn with damp leaves and dotted with clues to an industrial past such as a brickwork chimney in the background. Among the leaves are headstones from a former graveyard for cholera victims. The atmosphere is evocative and encourages users to bridge the gaps between the embedded item in the app image, the physical place, their own memories and stories they know. As these examples show, workshop participants and app users encountered the world of the archive by navigating an AR-enhanced geography. The invitation to see the space around the AR objects can be likened to the way Almond reworks the contemporary lived environment of the Ouseburn Valley, connecting it to its historical past.

In Heaven Eyes, the protagonists find themselves washed up on the 'Black Middens,' a bank of mud filled with buried mysteries. From the middens the characters observe 'ghosts' passing by on the other side of the river.

"There is ghosts everywhere," she said. "We eye them past where the runny water runs. We eye them in little boats. We eye them running on machines. We eye them way way down there where the bridges is. We ear when they squeal and scream and fill the night with noise" (Almond, 2000, p. 74).

Ghosts function as metaphors for the history of a place, but in Almond's writing they are also links to literary antecedents (myths, legends, ghost stories) and a signal that a place is a threshold to magical or otherwise inexplicable happenings. Each experience is changed by the AR encounter so the book is infused with memories of place and archival objects while the place evokes the atmosphere of the book and gives meaning to the embedded objects.

Another AR intervention played with the capacity of AR to create dramatic incongruities between digital objects and the physical environment. 'Clay' (Fig. 4) was a small doodle in notes for Almond's book of the same name. The app design worked not only to suggest possible future stories but also to put the users' bodies in new relationships with space. In the 'Clay' section of the app, the words appear as solid; white block letters reproducing Almond's original claylike and blocky script spell out the word. Focusing the word in the centre of the smartphone screen turns the lettering brown, and cracks start to appear and grow. Finally, the whole word crumbles to rubble.

The changing image captures the indeterminacy at the heart of Almond's novel (does Stephen have magical powers? Is the Golem real?) and, by blurring the boundaries between fact and fiction, gives form to magical realism as a literary mode (Faris, 2004). In much the same way, developing Almond's original lettering into a three-dimensional rendering complicates its materiality because of the way it is situated in an environment and so shares scenographic elements and geometry, creating a complicated sense of the unreal within the real. This comes 


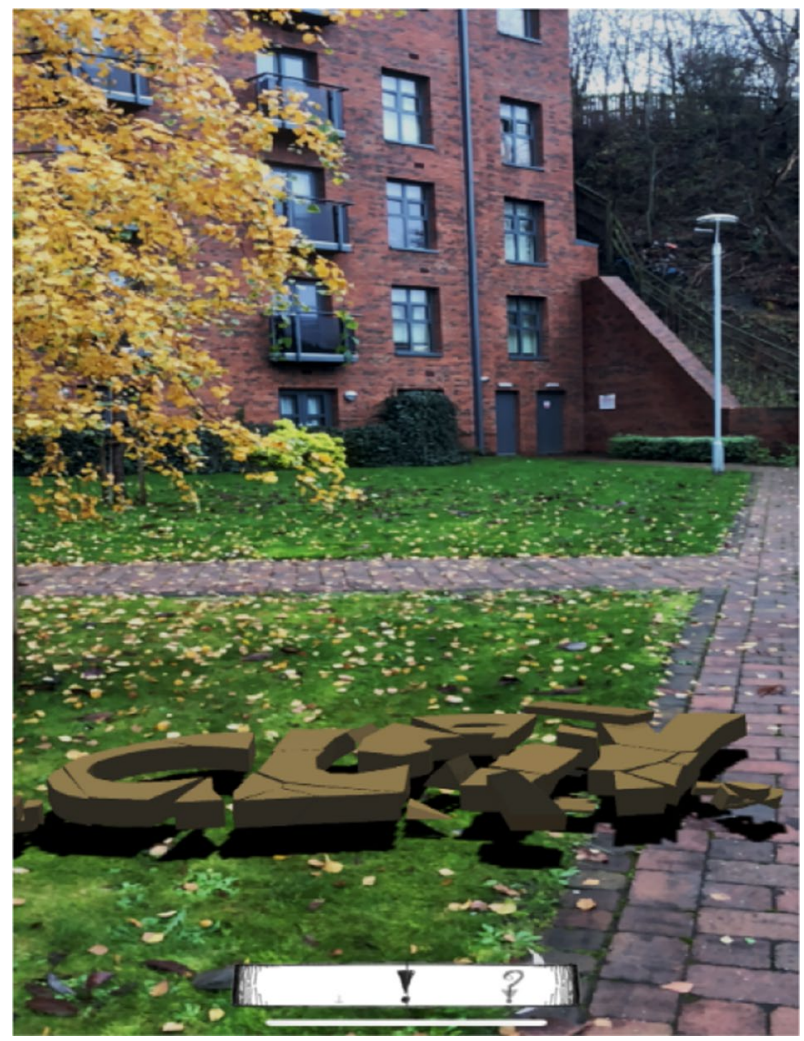

Fig. 4 Screen grab of 'CLAY' from Magical Reality

closer to notions of the fantastic in magical realism than more straightforward representations of magic in literature or technology.

As with 'clay', each item from the archive hovers between the real and the unreal as these thumbnail descriptions of them illustrate.

1. A drawing of a bird in cage outside the main Seven Stories building. The bird rotates to face users as they circle it, but the cage stays still.

2. A doodle with the words, 'grow up.' When users approach, a text box on the screen reads 'JUMP.' Sensors on the phone detect jumping motions and with each jump, the doodle grows.

3. A rising plume of smoke with the question, 'Have you ever seen the dead?' visible at its centre.

4. A drawing of the Cluny pub. It and the Seven Stories building are adjoined and were once the site of a print works which forms the setting for much of Heaven Eyes. Users passing through the object hear the recorded sounds of printing machinery. 
5. The words 'World is music' extruded into a solid three-dimensional form. As users approach, the form shatters into individual shards and the phrase is only legible from one particular angle.

6. The single word, 'clay' developed from a hand-drawn font into a solid rock-like form, as if the letters were formed from the same material. If the user keeps the item centred in the smartphone camera, it begins to crack and eventually crumbles into pieces.

\section{Texts, Workshops, App}

The workshops presented the 80 participants (these varied from session to session) with items that spoke to issues around the locality, magical realism, sites of memory and strategic transformations of place. Although magical realism as a mode was the starting point for the workshops and participants knew that an AR app was to be the outcome, no attempt was made to teach them about either magical realism or AR. Instead, the characteristics of each were distilled into tasks that required participants to think about unseen worlds, past civilizations and inexplicable phenomena in relation to the spaces immediately around Seven Stories. The majority of the workshops were conducted with children and in them researchers used narrative frames to recontextualise technology familiar to the children in their daily lives. The children were then asked to develop their own stories in response to the tasks. This was done not just to stimulate thinking that could be harvested for the project, but to give each workshop value to the participants in the form of ideas and outcomes relating to magical realism, space and place, memory, technology, and the Almond archives. A brief overview of the workshops gives some sense of how they evolved.

\section{Workshop 1: Magical Places}

This initial event explored ideas of co-existent or connected spaces by exploring a local tunnel, created in the nineteenth century to transport coal beneath the city of Newcastle. The children were asked to imagine that the tunnel was connected to another world and to choose places in the tunnel that they felt could serve as a portal to that world. They constructed portraits of the other world, including social, religious, physical or scientific rules that were different from their own world. The task aimed to focus their attention on how the experience of place links physical attributes to embodied and imaginary experiences.

\section{Workshop 2: Dreaming New Archives}

Taking as its starting point Almond's magical realist use of past times that infiltrate the present, this session used reproductions of material from the David Almond archive and presented them in a fictional frame. The frame described a fictitious archival accession donated by a stranger, oddly dressed and silent, who arrived at Seven Stories bearing a mossy, stained box. It was left with no explanation or 
context. The children were then set activities focused on understanding how the items in the old box, now part of the archive, had functioned in the invented civilization. The final task involved taking the items outside and relating them to features of the current landscape.

\section{Workshop 3: (Re)Making Memories}

Following on from ideas about the past as inscribed in the landscape and ancient objects, the third workshop focused on the relationship between memory and place, attempting to establish whether ideas around material or place-based memories are accessible to children and if so, in what form. Participants identified objects and sounds in the locality that 'remember', e.g. brick work that bears marks from old fires. They were encouraged to think about how sounds, objects, buildings and landscapes change over time.

\section{Workshop 4: Space, Magic and Devices}

This session was conducted in a local state school with Year 7 pupils (aged 11-12.) The aim was to explore children's ideas about how the fantastical and technological could co-exist. The main activity was building a simple electro-magnetic frequency detector which caused a buzzer to sound and a light to flash when it was near something electronic. They then produced short narrative accounts which populated the objects in the classroom to which their detectors had responded (light switches, printers, projectors) with characters from their imagination.

\section{Workshop 5: Children's Magical Realism for New Spatial Interactions: A collaborative workshop}

This workshop involved developers from some local AR/Virtual Reality studios as well as a broad cross-section of colleagues from the various departments of Seven Stories. A prototype of the app was tested.

\section{Workshop 6: Magical Reality}

The final session introduced a late stage version of the Magical Reality app to explore possibilities for building fictional narratives around the selected AR objects. The AR objects were presented as semi-mythical archaeological findings and participants were asked to explain what they were by relating them to a series of cryptic verbal cues.

\section{Key Workshop Findings}

Foremost among the understandings gained was that the children showed a marked tendency to see the concrete in the abstract and were drawn to overtly figurative 
items such as pictures of birds and boats. These insights shaped the selection of archival objects and the way they were treated in the final version of the app.

The children also seemed to feel the need to make sense of items in relation to one another. For instance, papers were sorted by what they perceived to be common motifs or evidence to explain how one thing or event could explain or complement another. This need informed the layout of Magical Reality; in it each item leads to the next, links were also made between what was visible from hot spot to hot spot, and the design worked to encourage users to consider how regarding them as either one large set or a series of small subsets might imply new meanings.

\section{AR and Children's Literature Looking Forward}

There is often suspicion of technology among proponents of the literary arts, who can be quick to dismiss emerging media and new developments in IT. Much has been written about the extent to which new forms tend to imitate their predecessors, not least to reassure established audiences (see, for instance, Bolter and Grusin, 1999). It is often the case that new technologies take time to find their voice and for their unique capabilities to be recognised. AR currently struggles to reach the same levels of sophistication literary texts can achieve, but as this project has shown, there are already valuable ways of employing it and other immersive technologies in the work of expanding access to and engaging new audiences in the use of the vast archives of museums, galleries and other cultural organisations. ${ }^{3}$ More than that, based on the reactions to AR in David Almond's North East, both experienced and developing readers find using AR to explore the geographies of texts they have read enjoyable and illuminating. It will be interesting to see if the opportunity to 'speak back' AR provides is taken up in relation to other texts and authors. Historical fiction, which often has strong links to particular places and landscapes, is an obvious opportunity and a way to help younger audiences develop a sense of how the past shapes the present. Eventually AR is likely to find its own narrative modes and offer original ways of telling stories, but while that capacity is still in formation, there is much to be gained by cultivating the relationship between AR and literature. The strong narrative drive of much writing for children and young people and youth's ease with digital technology could make an alliance between reading and $A R$ a valuable way of addressing issues such as repressive stereotypes and instances of neglect or silence around events from the past. Leaving aside social and political issues, such an alliance between AR and literature could be harnessed to help developing readers visualise locations, understand metaphors, and recognise generic traits. It seems worth trying to explore more fully the artistic and educational potential of the technology rather than leaving multinational chains to exploit it for commercial ends as in so many of the gaming applications where AR is currently most likely to be encountered.

\footnotetext{
3 While this is the first project to be based around a children's literature author and archive, other cultural bodies are also experimenting with AR's ability to bring artworks and texts into the everyday world where people may encounter them unexpectedly. See, for instance, the British Library project devised by Sarah Cole called 'Poetic Places'.
} 
Open Access This article is distributed under the terms of the Creative Commons Attribution 4.0 International License (http://creativecommons.org/licenses/by/4.0/), which permits unrestricted use, distribution, and reproduction in any medium, provided you give appropriate credit to the original author(s) and the source, provide a link to the Creative Commons license, and indicate if changes were made.

\section{References}

Abba, Tom and Duncan Speakman. (2013). These Pages Fall Like Ash project. Accessed on May 13, 2019 from http://www.wearecircumstance.com/these-pages-fall-like-ash/.

Almond, David. (1999). Kit's Wilderness. London: Hodder.

Almond, David. (2000). Heaven Eyes. London: Hodder.

Almond, David. (2005). Clay. London: Hodder.

Almond, David. (2007). My Dad's a Birdman, illus. Polly Dunbar. London: Walker Books.

Almond, David. (2008). The Savage, illus. Dave McKean. London: Walker Books.

Almond, David. (2014). A Song for Ella Grey. London: Hodder.

Bolter, Jay David, and Richard Grusin. (1999). Remediation: Understanding New Media. Cambridge, MA and London: MIT Press.

Butler, Catherine. (2018). Literary Studies Deconstructed: A Polemic. Cham, Switzerland: Palgrave Macmillan.

Cole, Sarah. (2016). Poetic Places. Accessed January 15, 2019 from http://www.poeticplaces.uk/.

De Certeau, Michel. (1984). The Practice of Everyday Life. Accessed January 15, 2019 from https://chisineu. files.wordpress.com/2012/10/certeau-michel-de-the-practice-of-everyday-life.pdf.

Duchene, Courtney. (December 12, 2016). The Flint Water Crisis and the PostIndustrial Ghetto: How the American Media Systematically Ignores Poor, Predominantly Black Communities. Odyssey. Accessed on December 31, 2017 from https://www.theodysseyonline.com/flint-water-crisis-postindustrial-ghetto, n.p.

England's Historic Cities. (2019). Heritage Cities. Accessed February 20, 2019 from http://www.heritageci ties.com/stories/explore.

Faris, Wendy B. (2004). Ordinary Enchantments: Magical Realism and the Remystification of Narrative. Nashville: Vanderbilt University Press.

Latham, Don. (2006). David Almond; Memory and Magic. Lanham, Maryland and Toronto: Scarecrow Press.

Liao, Tony and Lee Humphrey. (2014). Layar-ed Places: Using Mobile Augmented Reality to Tactically ReEngage, Re-Produce, and Re-Appropriate Public Space. New Media and Society, 17(9), 2014, 1-18.

Løvlie, Anders Sundnes. (2009). Poetic Augmented Reality. MindTrek '09, 19, 19-28. Accessed on January 15, 2019 from https://www.duo.uio.no/bitstream/handle/10852/27215/lovlie_poetic_augmented_reali ty_free_access_version.pdf?sequence=1.

Nora, Pierre. Between Memory and History: Les Lieux de Memoire. Representations, 26, Spring 1989, 7-24

Policy Exchange Blog Post. (November 13, 2012). The north's economy needs a radical new approach if it's going to catch up with the south. Accessed on December 29, 2017 from https://policyexchange.org.uk/ the-norths-economy-needs-a-radical-new-approach-if-its-going-to-catch-up-with-the-south/

Zuboff, Shoshana. (2018). The Age of Surveillance Capitalism: The Fight for the Future at the New Frontier of Power. London: Profile Books.

Publisher's Note Springer Nature remains neutral with regard to jurisdictional claims in published maps and institutional affiliations. 


\section{Affiliations}

\section{Kimberley Reynolds ${ }^{1}\left[\begin{array}{c}10 \\ \text { Tom Schofield }\end{array}{ }^{2} \cdot\right.$ Diego Trujillo-Pisanty $^{3}$}

$\triangle \quad$ Kimberley Reynolds

Kim.Reynolds@ncl.ac.uk

Tom Schofield

Tom.Schofield@ncl.ac.uk

Diego Trujillo-Pisanty

trujillo.dp@gmail.com

1 School of English Literature, Language and Linguistics, Newcastle University, Newcastle, UK

2 Culture Lab, Newcastle University, Newcastle, UK

3 Centro de Diseno, Cine Y Television, Mexico City, Mexico 